\title{
Gamelan Soepra: Konsep dan Perilaku Musikal untuk Mencapai Tujuan Pendidikan
}

\author{
Agustinus Sani Aryanto \\ Program Studi Musik, Fakultas Seni Pertunjukan, \\ Institut Seni Indonesia Denpasar \\ email: agustinussani@isi-dps.ac.id
}

\begin{abstract}
ABSTRAK
Gamelan Soepra adalah seperangkat gamelan yang diadaptasi dari gamelan Jawa dan memiliki nada diatonik seperti pada alat musik Barat. Dalam permainannya, gamelan Soepra dikolaborasikan dengan alat musik Barat seperti combo band dan string section. Gamelan Soepra diciptakan oleh seorang Jesuit asal Belanda bernama Henricus Constant van Deinse, SJ pada tahun 1957. Gamelan Soepra menjadi musik pendidikan di Sekolah Menengah Atas (SMA) Kolese Loyola Semarang, Jawa Tengah, sejak 2011. Penelitian ini bertujuan untuk mengetahui esensi dari gamelan Soepra sebagai sarana pembelajaran seni musik serta mendiskripsikan konsep, perilaku musikal, dan bunyi dalam musik gamelan Soepra di SMA Kolese Loyola Semarang. Metode penelitian yang digunakan adalah kualitatif dengan metode pengumpulan data observasi, wawancara, dan kajian literatur. Adapun pendekatan yang digunakan adalah musikologi untuk menganalisis instrumentasi pada gamelan Soepra. Data yang terkumpul dianalisis dengan menggunakan teori aktivitas musikal Alan P. Merriam untuk membedah perihal konsep, perilaku musikal, dan bunyi dalam gamelan Soepra dan teori dari Herbert Read untuk membedah fungsi pembelajaran gamelan Soepra sebagai sarana pendidikan seni musik di SMA Kolese Loyola. Hasil penelitian menunjukan bahwa SMA Kolese Loyola Semarang mempunyai metode tersendiri dalam mengenalkan gamelan melalui bentuk yang berbeda yaitu gamelan Soepra. Tangga nada diatonik dalam gamelan Soepra memiliki kekuatan dan kelemahan. Siswa menjadi lebih mudah dalam memainkan gamelan Soepra dengan berbagai genre lagu baik pentatonik maupun diatonik tetapi karakter tangganada pentatonik gamelan Jawa menjadi hilang. Melalui gamelan Soepra, siswa mampu mengenal kebudayaan Barat dan Timur baik dari alat musik maupun repertoar lagu yang dibawakan. Pengadaan konser rutin gamelan Soepra memberi pengalaman nyata bagi siswa baik dalam proses, persiapan, hingga pementasannya.
\end{abstract}

Kata kunci: Gamelan Soepra, karawitan Jawa, diatonik, musik pendidikan. 


\begin{abstract}
Soepra Gamelan is a set of gamelan adapted from Javanese Gamelan and has diatonic note like westen musical instruments. Soepra Gamelan is played with combo band and string section. Soepra Gamelan was created by a Jesuit from Netherlands Henricus Constant Van Deinse SJ in 1957. Soepra Gamelan has become a music subject in Loyola Senior High School Semarang since 2011. This research is to know the essence of Soepra Gamelan as a music learning means and to describe concept, musical behaviour, and the sound of Soepra Gamelan in Loyola Junior High School Semarang. Method in this research is qualitative using observation, interview, and literature study. This research is based on musicology approach. The approach is used to analyze instrumentalitation in Soepra Gamelan. The data is analyzed by using Musical Activity Theory by Alan $\mathrm{P}$ Merriam regarding the concept, musical behaviour, and the sound of Soepra Gamelan while Herbert Read theory is used to analyze the function of learning as a musical educational means in Loyola Senior High School Semarang. The result of this research is that Loyola Senior High School Semarang has a special method in introducing gamelan. Musical scale in Soepra Gamelan has an advantages and disadvantages (positive and negative impacts). Students can play many genre of songs in pentatonic and diatonic musical scale easily but, however, the characters of Javanese musical scale are disappeared. Through Soepra Gamelan, the students can recognize western and eastern culture from musical instrument and repertoire songs. Routine concert in performing the gamelan gives a real experience to the students in terms of process, preparation, and performance.
\end{abstract}

Keywords: Soepra Gamelan, Javanese karawitan, diatonic, music education.

\title{
PENDAHULUAN
}

Salah satu sekolah yang memberikan materi kesenian daerah yang relatif berbeda dari umumnya adalah Sekolah Menengah Atas (SMA) Kolese Loyola Semarang, Jawa Tengah, dengan alat musik gamelannya. Gamelan ini awalnya bernama gamelan Kromatik dan tahun 1965 berubah menjadi gamelan Soepra. Gamelan Soepra berbeda dengan gamelan pada umumnya karena Gamelan Soepra memiliki nada diatonik. Hal ini merupakan sesuatu yang baru karena gamelan pada umumnya mempunyai tangganada pentatonik yaitu pelog dan/atau slendro.

Gamelan Soepra merupakan buah perpaduan budaya Barat dan Timur yang termanifestasikan pada suatu musik berbentuk gamelan Jawa, namun memiliki 
tangga nada diatonik. Gamelan Soepra menjadi sarana pembelajaran seni di SMA Kolese Loyola Semarang sejak tahun 1957 hingga saat ini. Sekolah sebagai salah satu institusi pendidikan mendukung penuh pembelajaran gamelan Soepra sebagai wadah bagi pengembangan kreativitas siswa dalam bidang musik.

Gamelan Soepra di SMA Kolese Loyola Semarang menjadi sarana pendidikan seni musik baik itu intrakurikuler maupun ekstrakurikuler. Penulis membatasi ruang lingkup penelitian ini pada tahun 2011 sampai 2015, karena mulai tahun 2011 gamelan Soepra berkembang menjadi pembelajaran intrakurikuler yang wajib diikuti oleh semua siswa kelas $X$ (sepuluh) semester pertama.

KERANGKA TEORETIK: AKTIVITAS MUSIKAL SEBAGAI MEDIA UNTUK MENCAPAI TUJUAN PENDIDIKAN

Alan P. Meriam dalam bukunya The Anthropology of Music menjelaskan bahwa di dalam aktivitas musikal terdapat tiga elemen/unsur. Dalam setiap aktivitas musikal selalu terdapat conceptualization about music (konsep tentang musik), behavior in relation to music (perilaku tentang musik), dan music sound itself (bunyi musikal itu sendiri). Lebih lanjut di dalam behavior in relation to music (perilaku tentang musik) dibagi menjadi tiga yaitu physical behavior (perilaku fisik), social behavior (perilaku sosial), dan verbal behavior (perilaku verbal) (Merriam, 1964: 3233).

Bunyi musikal memiliki hubungan yang tidak dapat dipisahkan dari manusia. Bunyi musikal adalah produk dari perilaku manusia itu sendiri. Bunyi musikal mempunyai strukturnya sendiri dan berhubungan langsung dengan perilaku manusia. Perilaku yang dapat menimbulkan produk bunyi musikal terdiri dari perilaku fisik yang terlibat secara langsung dengan produksi pada postur manusia dan ketegangan fisik dalam menghasilkan bunyi musikal. Perilaku sosial terdiri atas perilaku dari seseorang sebagai musisi dan non musisi dalam suatu bunyi musikal. Perilaku verbal berkaitan dengan ekspresi dari konstruksi verbal dari sistem musiknya itu sendiri.

Tujuan pendidikan seni di sekolah umum adalah sebagai bagian untuk mencapai tujuan pendidikan. Seni merupakan alat untuk mencapai tujuan 
pendidikan. Di dalam pembelajaran seni siswa tidak dituntut untuk menjadi seniman, tetapi pendidikan seni menitik beratkan pada proses. Dalam proses pendidikan seni tersebut siswa dapat berkembang melalui berbagai proses pendidikan seni. Siswa diajarkan untuk mendapatkan pengalaman nyata dalam berkesenian. Melalui pengalaman nyata tersebut siswa diharapkan dapat berkembang potensi yang mereka miliki. Dalam hal ini seni sebagai dasar pendidikan seperti pada buku Herbert Read Education through Art.

Plato dalam tesisnya menyatakan bahwa "art should be the basis of education". Pendidikan seni mempunyai nilai yang tinggi di dalam dunia pendidikan. Tesis Plato tersebut dikembangkan oleh Herbert Read dalam Education through Art menjelaskan bahwa tujuan pendidikan,

"...the general purpose of education is to foster the growth of what is individual in each human being, at the same time harmonizing the individuality thus educed with the organic unity of the social group to which the individual belongs. It will be demonstrated in the pages wich follow that in this process aesthetic education is fundamental" (Read, 1970: 8).

Gamelan Soepra sebagai media pendidikan seni di SMA Kolese Loyola Semarang merupakan sarana untuk mengembangkan potensi siswa. Lewat pembelajaran musik gamelan Soepra siswa dapat mengembangakan potensinya, bahkan yang dimiliki sehingga dapat tumbuh dan berkembang sesuai dengan tujuan pendidikan.

Pendidikan musik di sekolah hendaknya juga digunakan untuk mengenalkan kesenian daerah Indonesia. Hal tersebut merupakan suatu kewajiban karena kesenian merupakan bagian yang penting dalam kultur suatu bangsa. Pada umumnya manusia menghargai keluhuran bangsa dengan mempelajari terlebih dahulu tentang kesenian rakyatnya. Ada kesenian, ada penghormatan; tiada kesenian, tiada penghargaan terhadap suatu bangsa (Dewantara, 2004: 334). Perilaku tersebut merupakan hal yang positif apabila generasi penerus bangsa ini diajarkan kesenian daerah Indonesia sebagai tanda penghargaan dan pelestarian kultur bangsa. 


\section{METODE}

Penelitian ini menggunakan metode kualitatif. Penelitian kualitatif digunakan untuk meneliti pada kondisi obyek yang alamiah (sebagai lawannya adalah eksperimen) di mana peneliti adalah sebagai instrumen kunci. Hasil penelitian kualitatif lebih menekankan makna dari pada generalisasi (Sugiyono, 2015: 15). Pendekatan yang digunakan dalam penelitian ini adalah pendekatan musikologis, dengan menganalisis instrumentasi pada alat musik gamelan Soepra.

Penulis melakukan pengamatan tanpa peran serta dan pengamatan berperan serta dalam proses pembelajaran dan pertunjukan gamelan Soepra di samping melakukan wawancara untuk dapat menemukan permasalahan yang ada. Jenis wawancara yang dipergunakan dalam penelitian kali ini ialah dengan wawancara terstruktur maupun wawancara tidak terstruktur dan dapat dilakukan dengan tatap muka (face to face) maupun dengan menggunakan telepon (Sugiyono, 2015: 194). Melangkapi observasi dan wawancara, penulis menggunakan teknik studi dokumen untuk mendukung data yang diperoleh.

Mengacu pada Miles dan Huberman (1992: 15-19), ada beberapa tahap dalam proses analisis yaitu periode pengumpulan data, reduksi data, penyajian/display data, dan penarikan kesimpulan/verifikasi.

\section{HASIL DAN PEMBAHASAN}

SMA Kolese Loyola peduli dengan kebudayaan Jawa yaitu gamelan, tetapi mempunyai cara sendiri dalam mengenalkan pada siswa. Gamelan ini hanya terdapat di SMA Kolese Loyola Semarang. Gamelan Soepra diciptakan oleh van Deinse dan diberi nama oleh Presiden pertama RI Soekarno. Nama Soepra diambil dari Uskup Soegijapranata yang menurut bahasa sansekerta "soepra" berarti super. Soepra menjadi ikon dan kebanggaan tersendiri bagi SMA Kolese Loyola Semarang. Munculnya pendidikan gamelan Soepra di SMA Kolese Loyola Semarang merupakan metode pendekatan pendidikan seni untuk mendekatkan seni itu sendiri kepada siswa.

Romo van Deinse menciptakan gamelan Soepra untuk kepentingan pendidikan seni musik di SMA Kolese Loyola Semarang. Tujuan awal penciptaan 
gamelan Soepra adalah mengembangkan (dan "menyempurnakan") gamelan Jawa. Romo van Deinse memiliki cita-cita bahwa melalui gamelan Soepra, siswa dapat memainkan karawitan Jawa seperti gamelan Jawa pada umumnya, tetapi juga dapat digunakan untuk memainkan lagu-lagu diatonis seperti alat musik Barat. Hal tersebut adalah suatu keunikan yang terdapat pada gamelan Soepra.

Beberapa hal yang diubah dalam penciptaan gamelan Soepra adalah tangga nada diatonisnya. Bentuk gamelan menjadi lebih tinggi dan panjang agar siswa dapat memainkannya dengan cara berdiri ataupun duduk. Gamelan Soepra dimainkan bersama dengan alat musik Barat, yaitu combo band dan strings.

Konsep, perilaku, dan bunyi musikal mempunyai keterkaitan satu sama lain (Merriam, 1964: 32). Keterkaitan tersebut juga berlaku pada gamelan Soepra di lingkungan pendidikan. Pengembangan gamelan Jawa menjadi gamelan Soepra menimbulkan konsekuensi tertentu, yaitu mengaburkan karakter gamelan Jawa. Ciri khas pèlog dan slèndro yang terdapat pada gamelan Jawa menjadi hilang, nadanada 'miring' dalam gamelan Jawa juga menjadi hilang. Meskipun gamelan Soepra masih dapat dimainkan lagu dengan tangga nada pelog dan slendro, tetapi tetap tidak bisa memainkan lagu seperti yang dimainkan oleh gamelan Jawa. Pola-pola imbal yang terdapat di dalam gamelan Jawa menjadi hilang digantikan oleh polapola chord. Gamelan Jawa sifatnya agung yaitu dengan suara yang berat tanpa adanya chord. Selain itu repertoar yang dimainkan gamelan Soepra lebih pada musik-musik diatonis, seperti lagu pop Barat dan Indonesia, lagu wajib Indonesia, dan juga lagu-lagu gereja yang digunakan untuk mengiringi misa Natal SMA Kolese Loyola Semarang. Lagu-lagu bernada pentatonik dimainkan gamelan Soepra pada repertoar lagu daerah Indonesia.

Di samping konsekuensi di atas, gamelan Soepra memiliki nilai positif. Melalui gamelan Soepra siswa dikenalkan dengan gamelan yang merupakan kebudayaan Jawa. Siswa menjadi mencintai gamelan karena memiliki tangganada diatonik, sehingga dapat memainkan semua genre lagu. Gamelan Soepra menjadi media ekspresi siswa melalui seni musik. Siswa berkesempatan memiliki pengalaman nyata dalam memainkan gamelan, dalam berbagai bentuk pertunjukan yang diadakan rutin setiap tahun. Di samping itu melalui intrakurikuler dan ektrakurikuler 
gamelan Soepra juga terdapat esensi pendidikan yang mengajaran tentang pendidikan karakter, yang mana siswa diajarkan untuk disiplin, bertanggung jawab, dan bekerja sama. Dengan demikian, Gamelan Soepra mampu menjadi alat untuk mencapai tujuan-tujuan pendidikan.

Penciptaan gamelan Soepra merupakan salah satu kreativitas dari Romo van Deinse. Makna kreativitas menurut Jacob Sumardjo adalah menemukan sesuatu yang baru dari sesuatu yang telah ada, maksudnya seniman menjadi kreatif dan besar karena bertolak dari bahan yang telah tercipta sebelumnya yaitu tradisi (Sumardjo, 2000: 84). Berangkat dari pendapat Jacob Sumardjo, bahwa gamelan merupakan tradisi dari kebudayaan Jawa. Pater van Deinse dengan kreativitasnya membuat gamelan Soepra dengan tujuan pendidikan seni di SMA Kolese Loyola Semarang. Gamelan Soepra menjadi suatu alat musik yang unik dan baru. Sumber bunyi dan wujudnya gamelan tetapi perilakunya bukan gamelan Jawa karena perubahan-perubahan yang terdapat di dalam gamelan Soepra.

Seni digunakan sebagai media dan seni sebagai alat (Read, 1970: 8-9). Melalui seni siswa dapat mengembangkan bakat dan potensi serta mencapai tujuan pendidikan. Pembelajaran seni dapat mengembangkan potensi yang ada di dalam diri siswa baik yang mencakup potensi fisik, mental, dan sosial siswa. Hal tersebut dapat terlihat dari konsep pembelajaran gamelan Soepra. Dalam proses pembelajaran intrakurikuler maupun ekstrakurikuler, dalam gamelan Sopera tidak hanya diajarkan bagaimana memainkan alat musik tetapi juga mengamalkan nilai pendidikan karakter yang ada di dalamnya. Pembelajaran gamelan Soepra juga mengajarkan tentang kebudayaan, hal tersebut terlihat di dalam setiap pembelajarannya.

\section{SIMPULAN}

Van Diense menciptakan gamelan Soepra bertujuan agar dapat memainkan berbagai genre musik, baik itu musik pentatonik maupun diatonik. Gamelan ini membawa dampak yang positif dan negatif bagi siswa. Dampak positif yang didapatkan adalah siswa dapat mengenal dan memiliki pengalaman dalam memainkan alat musik gamelan. Hal ini merupakan metode pembelajaran oleh SMA 
Kolese Loyola dalam rangka mengenalkan gamelan kepada siswa. Namun demikian, muncul dampak negatif, yaitu hilangnya karakter gamelan Jawa.

Gamelan Soepra menjadi sarana untuk mencapai tujuan pendidikan di SMA Kolese Loyola Semarang. Peran gamelan Soepra dalam pembelajaran seni musik sejak 2011 tersebut adalah mengenalkan berbagai kebudayaan Barat dan Timur dan mampu membangun karakter siswa. Melalui gamelan Soepra siswa dapat mencintai kebudayaan lokal dan terbuka terhadap kebudayaan luar. Gamelan Soepra mampu membentuk embodiment siswa dan mengarahkan mereka menjadi lebih disiplin dan bertanggung jawab.

\section{REFERENSI}

Dewantara, Ki Hajar. 2004. Pendidikan. Yogyakarta: Majelis Luhur Persatuan Taman Siswa.

Meriam, Alan P. 1964. Anthropology of Music. Evanston: Northwestern University Press.

Miles, Matthew B; Huberman, Michael A. 1992. Analisis Data Kualitatif. Jakarta: UII Press.

Read, Herbert. 1970. Education Through Art. London: Faber and Faber.

Sugiyono. 2015. Metode Penelitian Pendidikan Pendekatan Kuantitatif, Kualitatif, dan $R \& D$. Bandung: Alfabeta.

Sumardjo, Jacob. 2000. Filsafat Seni. Bandung: Institut Teknologi Bandung. 